\title{
Comment on Fochler and de Rijcke's "Implicated in the indicator game? An experimental debate"
}

\author{
MARILYN STRATHERN \\ UNIVERSITY OF CAMBRIDGE
}

For a one-time practitioner, it is fascinating to see something of the ways in which the indicator game has become embedded in academic life. The debate convened here by Maximilian Fochler and Sarah de Rijcke shows how the institutionalization of assessment has opened up academic lives to considered reflection. This is an interesting byproduct. More university researchers / teachers from more disciplines are ready to scrutinize, even evaluate, their working conditions than was ever the case in pre-audit days, if I may continue to use the shorthand of audit. In the process, the first person narrative often comes to the fore. Where the persona being narrated is that of the university academic, one might contemplate its relation to the authorial I of the scholar (not that they have to exclude each other). In any event, being invited to join this set of interested debaters, I need to declare my own credentials, or rather lack of them. A one-time practitioner indeed; if I share with Alan Irwin memory of the 1986 selectivity exercise at Manchester, it is also the memory of a then just-appointed chair and head of department, who could not have forecast that its last incarnation as the RAE research assessment exercise, in which she was also administratively involved, would take place in her retirement year (from another institution) in 2008. I give the date of retirement, because I always regarded that as disqualifying me from further intervention: I might still be a scholar, but am no longer the academic I was. My present stake in the university system is by proxy-through former colleagues, former students-and the value I give to the idea of the university gets enacted on few occasions. Above all, I no longer rub shoulders with administrators. It is important not to shrug off that loss of context.

The contributors to this experimentation in reflection on the academic as an interested party have laid issues that speak to the passage of time. If I may introduce another temporal dimension to those demarcated by Ulrike Felt, it is that of maturation. Alongside her trilogy of indices for the re-timing of academic careers and scholarly research, we might make a temporal horizon out of the "normalization" of the whole audit regime. We could imagine it as an analogue to the time it takes for the young researchers whom she mentions to gradually embody

Marilyn Strathern, Email: ms10026@cam.ac.uk

Copyright (C) 2017 (Marilyn Strathern). Licensed under the Creative Commons Attribution Non-commercial No Derivatives (by-nc-nd). Available at estsjournal.org. 
indicators through their self-auditing. For good or ill, duration has its own effects, and there are occasions when we need them. How, for example, do we give value to the time required for learning? Something that concerned me as a teacher was what was required for digestion and absorption in the maturation of ideas. Perhaps this was something like Julien McHardy's lazy space, a kind of lazy time, or perhaps Katie Vann's texts as generative environments in which minds take shape. Irwin brings to mind certain institutional and professional logics beyond immediate practice, and in a wider arena of perpetual innovation, ready enhancement, and indeed discovery known through on-time delivery, maturation-time becomes invisible. Yet we might still want to think about the process of growth, that is, of the kind of normalization or domestication through which people (gradually) make ideas and practices into intellectual devices that, importantly, they can operate. Maybe such "growth," with its organic imagery, was always an illusion, and new media overcome the time-lapse once integral to instilling skills. However, these essays are in themselves prime evidence of one kind growth.

A "problem" attributed to academics in the early years of auditing was their ready adaptability, their willingness to put themselves in others' shoes--including the shoes of beleaguered ministers for education and over-worked university administrators--and seeing other points of view. These are of course prime scholarly virtues, not least in the social sciences, and for STS and social anthropology alike. But academically-speaking they cede too much to other interests. Certainly in the UK, and with funding directly affected, it proved very hard for practitioners in higher education to narrate a counter-position. (In any event, the language of excellence and accountability had already been hi-jacked.) The point is that, so many years further down the line, it is evident how audit culture has grown. Fochler and de Rijcke's starting position is just how deeply it is sedimented into personal as well as institutional practice. Indeed, it surely says something about the way in which indicators and all they mean-such as their bearing on the meaning of work, as Ruth Müller talks of it-have become ingrained, if they [the indicators] can be framed within the terms of a "game." Serious play is evidence of maturation. In other words, this collection is a collateral reality (Felt's phrase), an index of time in the familiar guise of duration as a condition for change, including the changes implied in learning. Roland Bal's essay makes this very plain: the way in which his canny research group has at once tried to change the system, adapt to it and ignore it shows a maturity and coherence of response unimaginable thirty years ago. So, too, from an opposite vantage point, Paul Wouters and his colleagues took the extraordinary risk of engaging their actual auditors in a collaborative dialogue, as though intellectual well-being really were at stake, and in effect transformed that skeptical "really" into a reality. To put it briefly, the passage of time since the early days of academic assessment has had its effects. Is this a productive way to think of learning time (for growth), or might one instead take a cue from the huge energy being poured into indicator exercises, where-aside from specialist interests in the topic-learning time is spent in the form of what we often excoriate as "busy time"?

It is evident, as both Wouters and Irwin comment, that for all that one may describe the indicator game generically, there are significant differences across assessment regimes as well as between nationally configured relations of higher education bodies to one another, and the roles 
of centers and research groups alongside teaching and research departments. Then there is what can and cannot be negotiated, as Bal reminds us, namely what is open for play. One of the strengths of this collection, in a kind of contrast, is that the essays coalesce with a perspective from one discipline (homogeneity not implied, and albeit self-described as an interdisciplinary field). The reader could point to another index of growth in the extensive literature and number of STS authors from which and whom the convenors quote. The latter end their preliminary remarks with the hope that a new mode "evaluative inquiry" might emerge from more open engagement--not necessarily with auditors as in Wouters' experiment, or with themselves providing third-party vendor services for journals (Vann's academic evaluators)—but among themselves as STS practitioners. Evaluative practice as a taken-for-granted foundation of academic activity thus also becomes a playing field for scholarly work. The convenors' question is how one might mount an STS-sensitive evaluation of STS practices, and thus valorize STS work in its own terms. I have huge sympathy with the aspiration to turn the evaluation of STS into a method for self-scrutiny, in which indicators might or might not a play a part. I think it should be done anyway!- that is, not just as a positioning in relation to regime constraints. As an intellectual exercise it would display the contribution STS has to make to the meaning of (all) our academic circumstances, and make such skill evident across disciplines. For who else would be the recipients of the "evaluation"? Evaluation for whom? By comparison with what? One possible answer is "for" other academics undertaking other modes of inquiry, and thus "with" other disciplines.

In situating STS within a multi-valent interdisciplinary context, of which she has experience-based knowledge, Müller evokes its door-opening effect. Fully aware of the tension that evaluation introduces in the pursuit of disciplinary and interdisciplinary concerns, the latter is nonetheless envisaged as an arena where STS might show its impact. But what happens when "impact" itself becomes an indicator? From Müller's point of view, as Fochler and de Rijcke anticipate, I would say that the term is demeaned. We can see this in Vann's account of the outsourcing of impact in the computation of a journal's reputation: with the JIF as an indicator, the journal's impact factor becomes the author's impact factor. There is another example to hand in what has been happening in the UK with its renewed emphasis on impact factors in the current REF (research excellence framework).

Different kinds of performances, it is observed, require their own kinds of spectators; evaluation requires evaluators. My questions about who would be the recipient of STS autoevaluation re-invent one of the dimensions from which this set of essays seeks escape, namely giving too much weight to the heavy hand of the (official) auditor. Indicator systems will always have overflows, Bal says. Well, indeed, auditors themselves may wish to recede a bit from view too. When delivery becomes or acquires the idealized form of impact, then the receiving body (the auditors) can delegate front-line reception to another kind of outside party. So along with the new temporalization of the third-party funding body and its demands, justly pinpointed by Felt, comes another kind of third party. The reception of evaluation ceases to be simply a matter of report to the committee or panel sitting in adjudication on the differing scores of whatever units of assessment are being evaluated; that function is now, already, previously rehearsed by 
those other persons or bodies who have witnessed the impact that research has had on themselves. Such bodies have to be, by definition "exterior" to the producers of the research. So ploughing findings back into teaching, or illuminating colleagues, or growing the discipline-future generations regardless-do not count. Impact requires a demonstrable indifference to disciplinary development. Hence, for a while at least (I write from the years immediately after 2008, and may be out of date), showing interdisciplinary impact counted, and in anticipation UK research councils made interdisciplinary components of research applications a tick-box function. Needless to say, even better than other disciplines as outsiders were diverse and explicitly nonacademic "publics," with the gold standard being those that could register some kind of policyor commerce-generating outcome, symbolically as far from the idea of disinterested research process as one can get. (The ludicrous nature of these inside / outside bounding mechanisms becomes apparent.)

Now the REF (for a while anyway) allowed certain kinds of academic but commercial publishers, qua publishers, to count as third party impact-recipients, in terms for instance of auditees' relevance to publishing policy. It is not surprising, then, that elsewhere in this collection impact is disavowed, and it happens to be in this field: we are invited to consider not the impact a book might make but what it would be to care for a book. (Müller herself raised the question of how to care.) Here comes the breath of fresh air being blown by McHardy and his colleagues at Mattering Press, who deliberately work against competitive publishing that gives impact a calculative register. In the same breath, they take away the auditors' appropriation of "best practice" (there is no best practice, in their eyes, only experimentation). Formalizing the collaborative enterprise that producing a book-let alone a scholarly text--entails, they seem to be seeking out a certain quality of relating, their "relational achievement." This relating is to do with their care of authors and readers, and if I read aright is designed to complicate calculative evaluation, not least by simply making other possibilities for judgment more evident. We are back to evaluative inquiry.

It should be obvious that my own viewpoint is experientially informed by the UK academic / auditing regime. And here, most certainly, Felt's theatres of accountability continue to multiply. The games go on. UK universities are currently scrambling over themselves to put into place advisory and facilitative mechanisms to improve the chances of their researchers demonstrating impact, with real money from some (not all) of the research councils committed as well, for the latter are equally invested in the notion. (Anecdotally, the social science funding body, ESRC, is said to be overwhelmed by the [uniformly?] high quality of impact-returns.) This further round of professionalization is an example of institutional adaptability. Like adopting assessment procedures for their own internal government, universities draw into themselves the very practice of demonstrating impact. They enact, to appropriate Wouters' phrasing, the future they wish to bring about. Why, in a university context, do I raise an eyebrow here? We have already been given one answer. Whereas it is theoretically open to institutions to embrace a collaboration between parts of themselves, including their administrators, researchers and teachers, the professionalization of administration is another way of acting out the second set of factors on Irwin's list, "control at a distance." Administration becomes by definition performed 
as external to research and teaching. Administrators have their own meaning-agendas--their raison d'être is executive; in brief, it lies in making an impact. We need to understand them too.

In closing, let me say the obvious, that there is so much more to be drawn from this succinctly presented and highly finessed debate than these comments indicate. The iterative editorial process shows its mark, and creates if I may say a sense of collegiality among these accounts. Also evident is the expertise of several of the distinguished contributors who have made cultures of knowledge production, including research practice and its evaluation, their own field of scholarly interest. This is a deliberately specialist collection, and it shows exactly why we might continue to value specialists. The debate would be of great interest, for example, to current discussions in social anthropology, not as an indicator of its success, note, but as an effect of its intellectual specialization. If this STS discussion strikes a general chord among academic anthropologists, it will be for the differences as well as commonalities in their predicaments, for divergent as much as shared foundations of critical investigation, and for what both "disciplines" ordinarily wish to multiply, insights from diverse perspectives. But it also holds a particular and special interest for those who are professionally implicated in what they are studying. This we might say is the lot of anthropologists as fieldworkers: their relations with interlocutors and the systems under study are, often uncomfortably, also their socio-epistemic means of inquiry. Not to be dramatic about it, but they are forever in search of new rules-of-the-game. They would find much of illumination in this debate.

\section{Author Biography}

Professor Dame Marilyn Strathern is Emeritus Professor of Social Anthropology at the University of Cambridge. Her research has given us such ground-breaking anthropological books as The Gender of the Gift; Partial Connections; Kinship, Law and the Unexpected; Before and After Gender; and the widely influential Audit Cultures: Anthropological Studies in Accountability, Ethics and the Academy. 